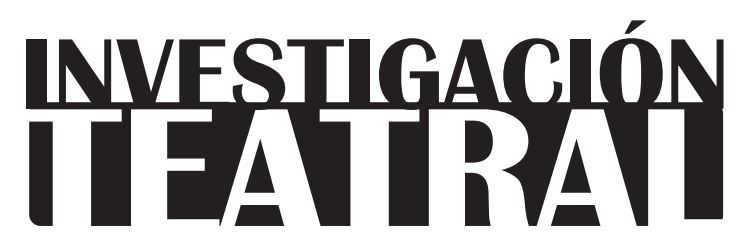

Revista de artes escénicas y performatividad

Vol. 11, Núm. 18

octubre 2020-marzo 2021

Segunda época

ISSN impreso: 1665-8728

ISSN electrónico: 2594-0953

Universidad Veracruzana

\title{
La reina de las polvaredas: contracultura, género y poder en Sol blanco
}

\author{
Pamela Torres Martínez*
}

\footnotetext{
* Universidad Autónoma de Ciudad Juárez, México. e-mail: pamtorresmar@gmail.com
}

Recibido: 02 de mayo de 2020

Aceptado: 20 de agosto de 2020

Doi: https://doi.org/10.25009/it.v11i18.2655 


\title{
La reina de las polvaredas: contracultura, género y poder en Sol blanco
}

\section{Resumen}

En México, y particularmente en las ciudades fronterizas, el fenómeno del narcotráfico ha devenido ya un estilo de vida que se ha transformado en una contracultura poseedora de su propia estética, vestimenta e incluso devociones religiosas ligadas a la violencia como pilar de su configuración. Este ensayo demuestra cómo, en su obra Sol blanco (1997), el dramaturgo Antonio Zúñiga plasma dichos comportamientos a través de personajes arquetípicos y situaciones que responden a imaginarios sociales cuya construcción se gesta mediante la identidad sexual de los actantes. Desde la perspectiva de género, se analiza la construcción de personajes tanto femeninos como masculinos, enfrentados a una jerarquía sistémica y al hiperviolento dominio "viril" que se vale de la desmedida brutalidad.

Palabras clave: narcocultura; feminicidio; dramaturgia; masculinidad; frontera norte; Ciudad Juárez, México.

\section{The Queen of the Dust Storms: Counterculture, Gender and Power in Sol Blanco}

\begin{abstract}
In Mexico and its border cities, drug trafficking has become a violent lifestyle and a counterculture that has its specific aesthetics, clothing codes and religious beliefs. This article addresses the way Antonio Zúñiga, in his play Sol blanco (1997), explores behaviors found in the narco world, by means of archetypical characters whose social constructions and sexual identity are inscribed in a systemic hierarchy. The play's female and male characters are discussed in light of gender studies to explore the way they confront a system of hyper-violent "virility" that exerts dominion through extreme forms of brutality.
\end{abstract}

Keywords: narco-culture; feminicide; dramaturgy; borderlands; masculinity; Ciudad Juárez; Mexico. 


\section{La reina de las polvaredas: contracultura, género y poder en Sol blanco}

"B ienvenido al engaño, a la mentira, al descrédito, a la orfandad" (Rascón, "Sol blanco") fueron las palabras con que dio comienzo Sol blanco, según anotó el dramaturgo Víctor Hugo Rascón Banda sobre la puesta en escena que realizó Octavio Trías en 1997 para el cuarto ciclo de Teatro Clandestino de Vicente Leñero. Heredero de los primeros esfuerzos mexicanos por llevar a la literatura la denuncia sobre el narcotráfico, Antonio Zúñiga examina la identidad de los traficantes de estupefacientes y la transforma en una propuesta escénica.

El tema al que se acerca el autor nacido en Ciudad Juárez, Chihuahua, había formado ya parte de la escritura mexicana por medio de esporádicas apariciones. Éstas comienzan en 1962, con la publicación de Diario de un narcotraficante de A. Nacaveva, y se reincide en ellas en pocas ocasiones, entre las cuales destaca El tráfico de la marihuana (1984) del mismo autor. En la década de 1990, conquista una cantidad enorme de propuestas artísticas: Contrabando (1991) de Rascón Banda, Cada respiro que tomas (1992) de Élmer Mendoza, y Juan Justino Judicial (1996) de Gerardo Cornejo se presumen, a su vez, como textos precursores.

Omar Nieto distingue en cada obra una evolución en la figura del narcotraficante: mientras que en Nacaveva es presentado como un ser de carácter honorable, cuyo negocio involucra nada más que el movimiento de los estupefacientes, en la década de los noventa nos encontramos con personajes que han sido víctimas de dicho movimiento, ya sea por medio del asesinato, el secuestro o la tortura. El escritor Omar Nieto señala a Juan Justino Judicial como un parteaguas en la representación de los sujetos del narcotráfico, pues "consigna claramente la violencia del capitalismo gore, en la que no puede diferenciarse el mun- 
do del narcotráfico y el de la narcopolítica, fundidos con el poder económico" ("Literatura y narcotráfico"). En Sol blanco puede entreverse esta sistematización de la violencia a partir de las tres problemáticas fundamentales de Ciudad Juárez, dotándola de gran vigencia: su estatus fronterizo, la brutalidad del narcotráfico y los feminicidios como parte del movimiento de estupefacientes.

En el presente trabajo busco determinar, dentro de Sol blanco, el papel de la contracultura del narco como un elemento determinante para la construcción de los personajes, quienes se constituyen a partir de tres ejes centrales: la detentación del poder, la religiosidad y la identidad sexual. Busco también encontrar cómo el género se convierte no sólo en un discurso identitario, sino también en un recurso que permite ostentar más o menos poder, según se aleje o se acerque el sujeto a los roles esperados de su género, los cuales se plantean como institucionalizados. Finalmente, pretendo demostrar cómo Sol blanco propone también una mirada hacia la discriminación basada en los recursos monetarios: los espacios donde se desarrolla la tragedia permiten comprender el nivel en la jerarquía de poder que exhiben los personajes, posicionándolos como bajos dentro del sistema del narcotráfico, aunque, aun así, generadores de niveles de poder entre ellos.

Con el pretexto de darle uso a un pequeño foro abandonado en la Casa del Teatro, Vicente Leñero propuso en 1995, el ciclo “Teatro Clandestino” que se dedicaría a la puesta en escena de un "teatro emergente, con obras sobre la realidad inmediata" (Todos somos Marcos). Las obras presentadas en aquel ciclo deberían crearse en un lapso de no más de treinta días: quince para su escritura y el resto para el montaje. Tras tres ediciones exitosas, el dramaturgo gestionó la cuarta (1997) con el objetivo de dar a conocer, como óperas primas, los trabajos realizados por los alumnos del taller de dramaturgia de la Casa del Teatro. Entre las obras presentadas ese año estuvo Sol blanco, de Zúñiga. ${ }^{1}$ Dirigida por Octavio Trías y montada por la compañía teatral juarense Alborde Teatro, estrenó en la Casa del Teatro en 1997 -de la fecha precisa no existe registro- y en el Teatro de la Nación del IMSS en Ciudad Juárez, Chihuahua, el 10 de septiembre del mismo año, con las actuaciones de Eréndira Astivia, José "Chato" Gómez, Gabriela Beltrán y Marco Antonio García (De la Mora y García Delgado 49). Su publicación se realizó hasta 1999, en la primera y única edición de Teatro clandestino publicada por Alborde Teatro en Ciudad Juárez, junto al texto de Todos somos Marcos, de Leñero.

Según la investigadora Rocío Galicia, la dramaturgia del norte se define, desde una primera instancia, como el corpus variado que ha resultado de la relación estrecha entre

1 Antonio Zúñiga (Parral, Chihuahua, 1965) es un dramaturgo, actor, director y promotor cultural mexicano. Ha sido acreedor del Premio Chihuahua 2012 y el xxxı Premio Nacional de Literatura José Fuentes Mares en el 2016, y actualmente se desempeña como director del Centro Cultural Helénico en la Ciudad de México. 
el entorno y la escritura teatral ("La dramaturgia actual" 1). Mientras que Galicia propone su origen alrededor de la década de los ochenta, por medio de los esfuerzos diferidos de varios dramaturgos que, al mismo tiempo en distintas ciudades, comienzan a trabajar para formar audiencias, compañeros creadores y espacios teatrales (4-6), Armando Partida lo define en una fecha concreta: durante 1984 se realiza la Primera Muestra de Teatro Regional del Noroeste, en Culiacán, Sinaloa (73), momento clave para la dramaturgia del norte, pues permite que cada uno de los participantes se identifique dentro de una estética particular.

Tanto Galicia como Partida señalan una serie de características que definen esta estética -a la cual Partida bautizó con el ahora poco usado nombre de "estética del desierto"-. Por un lado, la primera distingue tres líneas temáticas para la dramaturgia norteña: frontera, denuncia de aquello que acontece en el entorno y cultura patrimonial regional ("La dramaturgia actual" 8); por el otro, Partida considera una serie de elementos que permiten, en su conjunto, definirla: las problemáticas de la realidad fronteriza, la resiliencia de los indocumentados, la relación cotidiana con la muerte y sus distintas expresiones religiosas, el habla propia de la región, así como la insistencia en la forma musical, la revalorización de personajes históricos o legendarios y el análisis de los parajes propios del norte y el misticismo de sus grupos étnicos (74-91). Debido a su arraigo en la tierra norteña y, a diferencia de lo trabajado en el centro de México, la dramaturgia norteña prefiere "el intercambio y la formación de otros públicos mediante asuntos que atañen a situaciones contextuales más particulares" (Salcedo); esto permite, por tanto, que "A través del teatro, no hablan sus creadores, sino la sociedad de su tiempo" (Rascón citado en Galicia, "Asimilación de la realidad").

Es posible, pues, definir a la dramaturgia norteña como un esfuerzo de los autores por establecer "un diálogo crítico con su territorialidad, problemática, idiosincrasia, postura y preocupación social" ("La dramaturgia actual" 2). Atendiendo a la urgencia de la denuncia, las primeras obras dramáticas en las que aparece el fenómeno del narcotráfico en México pueden rastrearse a finales de la década de los ochenta. Iani Moreno identifica Guerrero negro (1988) de Rascón Banda como la primera, seguida por Lobo (1990) de Jorge Celaya, y las obras contenidas en la colección De los peligros que ocasiona el narcotráfico (1996) de Felipe Santander. La evolución del género ha pasado de enfocarse en el criminal a considerar el impacto que la figura del narcotraficante tiene en la sociedad (ibidem): desde la perspectiva de Galicia, el teatro del norte "interpela los mecanismos de la violencia contemporánea, los efectos y afectos en tiempos de desmesura y las implicaciones que el capitalismo tardío inscribe en los cuerpos de hombres y mujeres" ("Asimilación de la realidad").

Sol blanco explora el fenómeno del narcotráfico dentro de la frontera norte de la $\mathrm{Re}$ pública mexicana a través de una figura femenina, Blanca, quien se encarga de transportar 
cocaína escondida dentro de muñecas hasta Ciudad Juárez. Cansada de los peligros a los que se expone, pues cada vez hay más vigilancia en las garitas, Blanca decide escapar con Tony, llevándose la última carga de droga. Sin embargo, es descubierta por Cuca, su enamorada, y Chepo, su pareja; resueltos a no dejarla libre. La asesinan mientras la euforia de un partido de futbol, emitido desde un televisor, interrumpe la agonía de la protagonista, para después disponer de sus restos en la misma maleta donde la joven transportaba la mercancía. Tony se construye como el chivo expiatorio al encontrar el cuerpo desmembrado de la joven y mancharse con sangre las manos. Moreno considera que la obra de Zúñiga suele vincular el mundo del narcotráfico con sus repercusiones en la sociedad (137), demostrándolo vigente; sin embargo, Sol blanco se ha revisado en contadas ocasiones, entre las que destaca la presentación del libro Teatro clandestino realizada por Domingo Adame, y la reseña sobre el montaje de Trías que escribe Rascón Banda para la revista Proceso.

Considerándolo un dramaturgo prometedor, Adame aplaude la perspectiva voyerista que Zúñiga recrea: el mundo del narcotráfico es "visto desde el ojo de la cerradura" (13) y alaba el uso dramático del televisor (ibídem). Respecto a la puesta en escena, Rascón Banda considera que Trías y Alborde Teatro se olvidan de los elementos más impresionantes de la obra dramática para convertirla en un vórtice de brutalidad innecesaria y concluye aventurando que "Sol blanco es, quizá, el más arrebatado y tosco montaje que se le haya visto a Octavio Trías" ("Sol blanco"). Debido a lo expuesto, cabe señalar que el presente artículo se centra sobre la escritura dramática y no sobre la puesta en escena.

\section{Contracultura y configuración de personajes}

Luis Astorga y Oswaldo Zavala denuncian una cultura del monopolio de la violencia ante la cual han tenido que crearse figuras mitológicas que, como construcciones sociales, responden a la necesidad gubernamental de formarse un enemigo a combatir frente al cual los organismos de autoridad puedan resultar beneficiosos para la comunidad, constituyéndose como elemento salvador (Astorga, Mitología 135, Zavala, "Introducción" 9-10). Estos enemigos han encontrado cabida en los personajes del narcotráfico -mismos personajes que la investigadora y activista Sayak Valencia identifica como sujetos endriagos, extremando su caracterización al uso bestial medieval ("En el borde" 265)-, los cuales se han configurado a partir de una serie de características identitarias que, desde dos perspectivas, los conforman: la del enemigo, patrocinada por el acontecer gubernamental; y la del narcotraficante, expresada tanto en los delincuentes con posibilidades económicas como en aquellos que se encuentran en prisión. Zavala denuncia la "figura 
que del traficante el sistema político mexicano ha construido con fines específicos: un hombre vestido de vaquero escuchando narcocorridos" (9), portando "armas con chapas de oro, diamantes incrustados, todo con las iniciales grabadas del capo en turno" (ibídem); a quien se le describe, además, como un ser "indisciplinado, vulgar, ignorante, violento" (10). Así, la concepción del narcotraficante se concibe monstruosa y digna de persecución. Por otro lado, se ha propuesto esta figura como resultado de la creación personal de la identidad: Astorga señala que,

Como todo grupo social que llega a adquirir una cierta importancia y trata de crearse una identidad propia, que empieza a tener conciencia de sí mismo como grupo con características particulares que lo distinguen de otro, el de los traficantes de fármacos prohibidos entra a una etapa que podría caracterizarse como de transmutación del estigma en emblema (140).

Esto ha devenido en propios sistemas de ideales que abogan por la "construcción masculina hegemónica" (Jiménez, "Mujeres" 108) dentro del mundo del narcotráfico: los jefes se configuran como hombres valientes con un "repudio a la vida [...], acostumbrados a mandar, someter y controlar" (ibídem). Siguiendo la misma línea, América Becerra Romero explica la narcocultura como un "conjunto de acciones, enunciados y objetos significativos que conforman patrones de significado" (6), mediante los cuales se permite una comunicación entre sus integrantes. De esta manera, no se trata de una subcultura sino, como propone Astorga, de una contracultura basada en la violencia que se configura como "la oposición al marco axiológico de la cultura dominante" (136), cuya característica primordial es la "actividad ilegal de transportar y comercializar drogas ilegales" (Ovalle y Giacomello 300). Esto último ha permitido la instauración del narcomundo como ese sistema contra el cual ha de batallarse, debido a que su pilar, el comercio de drogas, atenta contra la salud, según el discurso oficial operado por las instituciones dominantes.

Mientras Felipe Fuentes Kraffczyk relaciona a esta contracultura con un potencial revolucionario, pues se trata de un "nuevo gran poder [...] capaz de cimbrar desde la raíz al 'orden convencional' al posibilitar la emergencia de nuevos colectivos, de carne monstruosa" (28), Astorga la relaciona con la salud. Señala que desde el siglo xix el bienestar de una nación ya se identifica con la salud física de sus habitantes y con la pureza de su sistema jurídico-policíaco, debido a la idea de que "un cuerpo físico y un cuerpo social sanos son necesarios para el mantenimiento del orden y el logro del bien común" (9). La contracultura se crea desde la enfermedad que supone la inversión de este sistema sano: la comercialización de drogas como un agente corruptor del orden social puede verse reflejada en Sol blanco a través de la corporalidad. René Girard propone el tema 
del veneno como la justificación de la persecución que se realiza dentro del sistema, pues se imaginan, en este caso, las drogas y sus agentes de producción y distribución como "concentrados tan venenosos que en cantidades ínfimas bastarían para emponzoñar poblaciones enteras" (26).

En la obra de Zúñiga, estas producciones tóxicas se convierten en amenazas que no sólo se ciernen sobre los individuos de la sociedad intoxicada, sino que marcan, como un estigma, a los personajes. Fuentes Kraffczyk considera que el cuerpo se debe entender a través de dos dimensiones: como cuerpo humano y como cuerpo social; esto supone una relación inversa entre el estado de lo físico y la asociación que socialmente maneja: "conforme su físico se despedaza, su organización criminal crece hasta límites insospechados" (23), mientras que la sociedad se ajusta directamente con "una sociedad en decadencia, lacerada y atrapada en una espiral de destrucción" (26). Así, identifica "la transformación o incluso destrucción del cuerpo" (21) como un elemento que resulta recurrente en las recreaciones artísticas del narcotráfico.

Representantes del sistema enfermo que propone el discurso oficial, los pies de Chepo sufren una picazón que no permite la andanza: "Tus pies reflejan lo qué [sic] tú eres o cómo estás. Si tú estás bien, tus pies están bien, pero si tu [sic] estás mal, tus pies se ponen así; duros, rugosos, resentidos" (Zúñiga 65), le dice Cuca a Chepo mientras le realiza un lavado. El tratamiento que se hace sobre los pies de Chepo, así como el resto de sus características físicas, que se adivinan grotescas en tanto el comportamiento del personaje obedece a la hipersexualidad, parece responder al montaje creado por las autoridades y auspiciado por la prensa, el cual muestra a todo supuesto narcotraficante como "naco": "sin rasurar, despeinado, desvelado, sucio, en camiseta o con la camisa abierta, sosteniendo un arma" (41). Como personaje arquetípico, Chepo muestra las características que lo marcan como integrante de la contracultura: la apariencia de sus pies lo edifica como personaje "naco". Él sabe lo que sucede con sus extremidades y encuentra él mismo el simbolismo de éstas a través de su cuidado diario, pues cuan largas crecen sus uñas evidencia su trayectoria dentro del sistema del narcotráfico: "Cuando uno se arrepiente de cómo ha vivido, quiere echarse de reversa, pero no se puede. No queda más que derecha la flecha. Aunque se la pase uno cortándose las uñas para que no lo delaten” (Zúñiga 65). La entrada al juego del narcotráfico se torna decisiva: la deserción, imposible, se convierte en la traición al sistema, del que Blanca es doblemente traidora, pues no sólo plantea su escape a través de Tony, sino que traiciona también las circunstancias personales de Chepo, quien forma parte de un sistema jerárquico mucho más amplio, al desdibujarse del mundo del micro-tráfico.

Resulta interesante que, junto a la salud física de los habitantes de un Estado, sea necesaria también la pureza de sus autoridades. Astorga denuncia la idea de un poder 
corruptor externo cuya aparente influencia erosiona la integridad de las instituciones, pero señala que en realidad dentro de los organismos mismos se ha gestado esta erosión "sin 'contaminación' exterior" (10). "El dinero es el fin y las drogas el medio más rentable" (11), continúa el sociólogo mexicano, por lo que para el cómodo tráfico de sustancias ilícitas se convierte en necesaria la relación entre las autoridades y los sujetos narcotraficantes (77). Chepo se muestra preocupado porque el "comandante", quien ha de administrar el encargo que lleva Blanca consigo en las maletas, lo está presionando: "El comandante se ha puesto muy delicado", le comenta a Cuca, "pero no creas, el miedo es cabrón Cuca. Y esos güeyes no se andan con chingaderas a la hora de pedir cuentas" (Zúñiga 59). Astorga señala que si bien las autoridades intervienen en las tramas de la ilegalidad, no por ello dejan de ostentar el poder que oficialmente detentan desde un inicio (77). Se adivina la edificación de un sistema gigantesco de la narcocultura, en el que intervienen personajes de todas las gamas y clases sociales, pero donde también existe una jerarquía que compromete el comportamiento de cada uno de sus integrantes y que, a la vez, se muestra como un esquema definido que permite dirigir la mirada hacia los más vulnerables dentro de dicha escala.

De la misma manera, Sol blanco hace evidente el miedo provocado por los agentes aduanales, quienes al mismo tiempo se encuentran inmiscuidos en el tráfico de la droga: "Eso de que nadie la molesta es puro cuento chino. Siempre es un albur con las madrinas y en camión peor" (61). Así, Blanca se presenta como el eslabón más débil, en quien recae la violencia con todo el peso del sistema; síguele Tony, quien por su cobardía falla al sistema de género propuesto por la narcocultura (ver Jiménez 108); y se alzan como figuras idénticas Chepo y Cuca. Zavala sugiere que el narcotraficante no es más que el "lenguaje oficial que lo inventa" (24): por esto, Chepo funciona como un arquetipo que se inserta en una jerarquía de poder. Sobre ellos se levantan los policías aduanales y la misteriosa efigie del comandante, quien gobierna y dispone a su gusto del encadenamiento mencionado. Sobre el miedo como herramienta se hablará en el tercer apartado.

Dentro de la narcocultura se localiza también como parte primordial la religión, ${ }^{2}$ debido a que el "constante acercamiento de los traficantes con la violencia y la muerte genera la necesidad de buscar protección en figuras sobrenaturales a quienes se pueda encomendar la buena fortuna y sobrevivencia" (Becerra 19). Gracias a la cultura a la que se opone el mundo del narcotráfico, sus religiones se identifican como sincréticas, pues mezclan los íconos católicos con figuras religiosas que se reinterpretan a provecho de los fieles, creando

2 Véase el artículo que sobre la experiencia de la Santa Muerte escribe Guadalupe Vargas Montero: "De devoción tradicional a culto posmoderno. La Santa Muerte en el norte y sureste mexicano" (2017), en el que realiza un estudio etnográfico de los creyentes de este culto en Ciudad Juárez y Veracruz. 
efigies que "son tan transgresoras del orden social como los propios traficantes" (20): Malverde, Nazario Moreno y la Santa Muerte son tan sólo algunos de los íconos que absorben los elementos propios de las iconografías católicas y se muestran unidos a ellos, en "una expresión que emerge del sector social más desprotegido como respuesta ante el orden dominante" (Gudrún citado en Hernández 20), donde "los valores y principios de la iglesia católica se invierten" (Vargas 132). De esta manera, no es extraño encontrar a la Santa Muerte disfrazada con los atuendos de la Virgen María o a Malverde metamorfoseado en San Lorenzo (126).

En realidad, la presencia de los santones, particularmente en el norte de México, está fuertemente arraigada a las tradiciones de cada comunidad, por lo que no es infrecuente encontrarla dentro de las letras norteñas. ${ }^{3}$ Al respecto, Galicia considera que su lugar corresponde no tanto a la literatura en general, sino más bien al ámbito de las letras, pues "la dinámica narrativa de la mística popular resulta un campo sustancioso que reclama una mirada capaz de observar procesos móviles y no congruentes" ("Los santos apócrifos"), siendo ésta el teatro en tanto sus textos "se abren a múltiples interpretaciones, las cuales transitan entre la apología, la crítica feroz, la humanización de lo místico o el análisis social" (ibidem).

Cuca misma representa este sincretismo planteado, el cual se ve potenciado en los actos blasfemos que realiza, identificándose alternadamente con los nombres de aquellos que se consideran santos o sacros según la religión católica:
Soy la virgen
Soy María Guadalupe
Soy María Concepción
Soy María Magdalena
Soy una puta... (50)

Lo mismo sucede con Blanca, a quien Cuca identifica con la Virgen María y hacia quien dirige sus oraciones previas al acto sexual: "Dios te salve Blanca [...] / Bendita Blanca entre las mujeres [...] / Y bendito el fruto de nuestro vientre" (51), denotando el comportamiento lésbico mediante una masturbación disfrazada de muñeca llevada al

3 Véase Ánimas y santones: vida y milagros del niño Fidencio, el Tiradito y Malverde, una antología compilada por Rocío Galicia, en la que se presentan las propuestas dramáticas de tres autores: Enrique Mijares, Alejandro Román y el propio Zúñiga, sobre las figuras de estos personajes del sincretismo religioso. El tiradito. Crónica de un santo pecador es la obra presentada por Zúñiga; de hechura más reciente (2002), que explora la figura de Juan Olivares, santo de los migrantes. 
sexo" (51). Posteriormente, continúa emulando comportamientos sacros: a través del lavado de pies se mimetiza con el personaje de María Magdalena, pues incluso utiliza agua infusionada por yerbas (63), a manera de perfume. Bajo la ilusión de escapar acompañada de Blanca, le da un baño aromático que simula el bautismo, buscando estimular así la afección homosexual.

Andrew Chesnut señala que la Santa Muerte "pasó de ser una doctora de amor [...] a erguirse como uno de los seres sobrenaturales más populares en México y Centroamérica, que maneja todo tipo de petición más allá de los asuntos del corazón" (9). Los rituales que Cuca realiza abarcan la totalidad de la amplia gama seguida culturalmente por la "Dama Blanca". Relativos a la protagonista, estos rituales son de amor pero, auxiliada por la cocaína, Cuca se desempeña como una mediadora que transita entre el mundo de los vivos y el de los muertos, con el que puede comunicarse: "Tú te conformas con chuparte el polvo para hablar con los muertos, sin riesgo, sin miedo, sin el puto miedo" (69), le reclama Blanca. Su figura alude a la de una bruja, de modo que en la primera escena de Sol blanco se muestra dentro de una habitación periférica, acompañada de las veladoras que ha puesto sobre un nicho, en el cual hay una muñeca que representa a Blanca (50), cuyo nombre se asemeja a aquellos dados a la Santa Muerte: "Niña, mi Niña, la Niña Blanca, Niña Bonita, Blanquita" (Vargas 111). La ritualidad de la escena parece atribuirse al alcance que el sincretismo posee en la religiosidad de la narcocultura, pues se mezcla también con la santería, el palo mayombe o el espiritismo (Chesnut 10), y se propicia dentro de los escenarios periféricos (Moreno 117) y privados (Vargas 116). Sin embargo, el asesinato de Blanca se postula como una posibilidad más de la religiosidad de Cuca: "la violencia actual debida al narcotráfico en México parece ser encabezada por individuos que utilizan santones para causar destrucción, violencia, dolor y muerte" (Moreno 115); ; así, la mutilación que Cuca efectúa parece ser únicamente el eco de otras mutilaciones: “iTe gusta cortar, eh?” (Zúñiga 74). Vargas Montero encuentra una relación entre el sacrificio de personas y ritos iniciáticos para el culto de la Santa Muerte: los plantea como asesinatos efectuados por el sicariato (30). Blanca, desde esta perspectiva, no es sacrificada a cambio de la obtención de un bien mayor, ${ }^{5}$ pero su muerte sí forma parte de una ritualidad.

4 "The current violence due to narcotrafficking in Mexico appears to be spearheaded by individuals who use santones to cause destruction, violence, pain and death".

5 Véase el popular caso de Sara Villareal Aldrete y Jesús Constanzo, quienes consideraban que la ventura de su banda de narcotráfico se relacionaba directamente con sacrificios humanos (Washington 59). 


\section{Género y violencia en Sol blanco}

El papel de las mujeres en el mundo del narcotráfico es más bien limitado. Ya señalan de manera precisa Paola Ovalle y Corina Giacomello cómo la contracultura del mundo de los estupefacientes no hace sino remedar de manera extremadamente exagerada los constructos sociales y de género de la cultura institucionalizada (298), de manera que los roles pueden percibirse con bastante mayor claridad. Las autoras ven el narcomundo como un "sistema esencialmente machista, donde se reproduce en forma caricaturesca el 'orden' social instaurado artificialmente sobre la base del supuesto de la superioridad masculina” (300-301).

De esta manera, la posición de las mujeres dentro de la narcocultura es precisa e inamovible, y puede clasificarse con facilidad en categorías bien diferenciadas: mujeres-trofeo, cuyo valor reside en el atractivo de sus cuerpos; madres, esposas o hijas de narcos, "para quienes ese particular mundo constituye su medio natural" (297), y trabajadoras, quienes han decidido incorporarse de manera profesional al mundo del narcotráfico (298; Acosta 10).

El personaje de Blanca se construye mediante las tres categorías: su apariencia física, que la ha convertido en reina de belleza, permite que se entreviste de manera directa con el narcotráfico a través de la atracción sexual que por ella desarrolla Chepo: "Si estaba toda brillosa: el pelo, los cachetes, no sé si por el solazo o por el vestido que se puso usted. Parecía estrella de navidad, nadie la podía ver por la encandilada que les ponía" (Zúñiga 68-69). Ya Jiménez encuentra que "La belleza y el narco se han relacionado de tal forma que son varias las reinas de belleza vinculadas a narcotraficantes" (111), pues estas mujeres acompañan a los delincuentes como si de un adorno se tratasen: la calidad de "esfera de discotec" (Zúñiga 69) de Blanca responde a la necesidad de Chepo de mostrarse con una mujer-objeto que comunique "a la sociedad con la que interactúa su éxito en términos de riqueza y poder social” (Ovalle y Giacomello 304-305). Así, el cuerpo de estas mujeres-trofeo adquiere importancia en tanto se moldea según el deseo masculino y se vuelve apetecible para éste (Jiménez 110): Blanca funciona entonces como una manzana de la discordia cuyo cuerpo se convierte en objeto de deseo para el resto de los personajes, masculinizados en tanto el erotismo entre la protagonista y ellos se establece.

Sin embargo, Blanca pierde sus privilegios de mujer-trofeo en cuanto se convierte en madre y comienza a poner la existencia de su hija antes que la de su pareja: "Además ésta no trae nada [...] Es un regalo para mija" (Zúñiga 53), le dice a Tony para desinteresarlo sobre el contenido de la maleta. El cambio de interés de la madre la transforma en una de aquellas mujeres cuya fuente de ingresos surge con el micro-tráfico de droga: “Ahora qué quieres? ¿Dinero? Pues gánatelo, ya sabes cómo. Nada te va a pasar por cargar maletas y viajar” (69), 
le dice Chepo a Blanca, dejándola desamparada en la crianza de su hija; de esta manera, la protagonista es orillada al negocio de las drogas, en donde ha de funcionar como mula. Siendo una mujer bella, Blanca se degrada de mujer-trofeo a agente del micro-tráfico por el mero hecho de la gestación. La problemática que expone el dramaturgo a través de Blanca-mula no es solamente la degradación por la adscripción al rol de género, sino también el peligro que estas mujeres, por una nimia cantidad de efectivo, deben atravesar. Las redes del narcotráfico las utilizan como "últimos eslabones en sus cadenas laborales asignándoles las actividades más riesgosas y mal remuneradas" (Ovalle y Giacomello 308) -Astorga señala que las cárceles están llenas del último eslabón de la cadena (87)-. Y acaso su situación de género amplifique la vulnerabilidad a la que se ven sometidas por moverse al margen de la ley, convirtiendo su cuerpo en un espacio donde la ley no se aplica: "Ustedes no saben lo que es rogarle a no sé qué demonios para pasar con vida el retén, para que no abran la maleta ni te aprieten las nalgas o te metan los dedos los pinches madrinas" (Zúñiga 69).

Contraria a Blanca, Cuca se configura como un personaje alto en la escala del narcotráfico. Ovalle y Giacomello cuestionan si el narcomundo puede propiciar la visualización, por su carácter de contracultura - pues se opone a un sistema patriarcal que no admite un cambio dentro de los roles de género-, de espacios de lucha y de resignificación de lo femenino (314-315); Acosta Viera considera que sí existe un nivel alto en donde las mujeres pueden poseer puestos de mando, pero éstos se ven limitados a féminas con "una personalidad fuerte [...] intimidante, como la de los hombres, lo que les permite escalar a puestos con autoridad" (9).

Blanca, que considera independizarse y escapar del negocio de Chepo, por su condición de "muñeca" no logra en ningún momento elevarse sobre quien se posiciona como su dueño. Sin embargo, Cuca sí logra alcanzar el espacio de poder al que apunta Blanca. Si bien ninguna acotación indica la vestimenta de esta última, se adivina femenina, a la manera de las muñecas que lleva consigo; por el contrario, desde el inicio, la ropa de Cuca se intuye masculina: "Cuca viste pantalón de pechera y camiseta" (Zúñiga 50), aconseja para el montaje la acotación. La atracción no normativa que Cuca siente por Blanca también la posiciona como un macho dentro del juego sexual: "Tú eres un macho, como él. Me das miedo" (75), admite la joven ante la insistencia de Cuca. Su función como aquella que "corta" la ayuda a fortalecer la virilidad de la que es partícipe, pues "el arma punzocortante es un sustituto del pene del atacante" (Washington 61).

La misma identidad corrupta de Cuca funciona como un potenciador para la masculinidad de Chepo, quien se esfuerza no sólo en demostrar su dominio sobre Blanca, sino también sobre Cuca; así, mientras ella le hace el lavado de pies, "Chepo se pone de pie y le acerca el pubis a la cara" (64). Su afirmación como "macho" requiere apoderarse también de la masculinidad de Cuca, considerando su sexualidad lésbica como una "fantasía 
de la reproducción" que se vuelve legítima sólo en tanto es un momento transitorio en la heterosexualidad (Ahmed 251), es decir, sólo en tanto se entiende como un juego a través del cual el personaje heterosexual es capaz de llegar a la excitación: "Otra vez jugando juntas" (72), les dice Chepo a Blanca y Cuca cuando las descubre en el encuentro sexual, para luego alcanzar con su mano la entrepierna de su pareja (ibídem). De esta manera, Chepo pone a prueba su dominio sobre el cuerpo femenino en un desplante homofóbico, cuya acción -la toma del cuerpo de Blanca- lo posiciona como "verdadero" dueño de ambas: "Quién las viera tan hembras y nada, les encanta tocarse las mañanitas, se les hace agua la canoa" (ibidem).

Los papeles que desempeñan Blanca y Cuca, como representantes de dos niveles muy distintos dentro de la escala de poder en el mundo del narcotráfico, se ven reforzados por la presencia de las muñecas dentro de la obra. Simbólicamente, estas figuras representan a Blanca, hecho que se antoja aparente tan pronto comienza la obra, pues Cuca la pretende en forma de muñeca: llevándola a su sexo, "se frota con ella y apaga las velas" (Zúñiga 51). Lo mismo hacen Tony -quien, si bien no juega con la muñeca, sí se dirige a Blanca con apelativos que se le parecen: "Si pareces de pan, como semita caliente, toda lisita, sin marca en la piel, bonita, Blanca, chiquita" (57)-, y Chepo, cuyas palabras pueden encontrarse en el recuerdo con el cual Blanca empieza su intervención en Sol blanco: "Parece muñequita blanca, una de esas barbies de pelo güero y de cachetes rojos como manzana, por algo te hiciste reina, por algo estás conmigo... por bonita... por blanca..." (52). La identificación de Blanca con las muñecas y el acto de consumo que Cuca realiza del contenido de éstas simulan de manera efectiva el acto sexual al que se entregarán los dos cuerpos femeninos; a su vez, permiten la confirmación del asesinato de Blanca como un feminicidio.

Si bien la protagonista no corresponde al perfil hacia el cual apunta el delito del feminicidio en Ciudad Juárez (las víctimas suelen ser mujeres trabajadoras de la industria maquiladora, cuyas características más distintivas son el cabello negro largo y piel morena -apariencia contraria a la de Blanca, como se verá más adelante-), su asesinato puede comprenderse desde múltiples puntos de vista, entre ellos el del fenómeno de los feminicidios sexuales sistémicos (ver Monárrez 95).

Por desgracia, la violencia forma parte tan esencial de la narcocultura que se explica como reacción natural hacia los estímulos negativos (Ovalle y Giacomello 313). La muerte de Blanca se yergue ante ésta como un destino del que no puede escapar. De esta manera, su asesinato se traviste de otros tantos: es un feminicidio que aparenta ser un crimen pasional y que, al mismo tiempo, se justifica como un crimen saldo del narcotráfico debido a la traición que efectúa. Si bien por su carácter de dominación, Cuca encuentra el bienestar en una transición identitaria, en un travestismo ritualístico - "Soy Refugio 
Armendáriz... / Soy Cuca Armendáriz / Soy María Armendáriz..." (50)-, el entendimiento de los cuerpos por medio de un nuevo sistema de significación (Ahmed 249) le está prohibido a Blanca, incluso en la muerte. La carga simbólica de su nombre, que la apresa y la condena, no apunta únicamente hacia la droga que transporta a lo largo de la República -"Haz de cuenta que cargas tierra, o polvo del desierto. Así de fácil como cargas tu nombre, anímate, no tengas miedo, ya luego te voy a hacer reina" (Zúñiga 69)-, sino también hacia la pureza que del personaje se espera. Los feminicidios en Ciudad Juárez se presentan como un delito dirigido hacia las jóvenes de piel morena, de quienes se cree, a diferencia de las blancas, que son "más proclives de "caer en tentación"' (Monárrez 107): las jóvenes blancas se construyen, entonces, como "mujeres puras" que no tienen que ser castigadas (ibídem). El pecado de Blanca, sin embargo, redime la acción que sobre ella se gesta: pierde su valor como "mujer pura" en tanto se entrega a los deseos eróticos sugeridos por Cuca y Tony; su asesinato se ejerce con la impunidad de quien castiga aquello que le pertenece por derecho propio (Jiménez 108). Así, Chepo repite una y otra vez: “Pinches viejas, todas son iguales!” (63) tras darse cuenta del desencanto que le plantea Blanca, que ha dejado de ser el ente puro que idealizaba para sí como mujer-trofeo. De la misma manera, su trabajo como mula desestima su valor en el negocio, lo que rebaja el nivel económico de su cuerpo y la vuelve susceptible al feminicidio (Monárrez 105).

Blanca se sugiere entonces ya no sólo víctima de Chepo y Cuca, sino parte de un sistema que la condena por mostrar comportamientos que de ella no se esperan, desobedeciendo el sistema del capitalismo representado en el necropoder de la droga y su venta ilícita (Valencia, "This is what" 109); se metamorfosea su cuerpo para servir no sólo como herramienta para el castigo sino para una nueva amenaza.

Rita Laura Segato identifica dos leyes del patriarcado: "la norma del control o posesión sobre el cuerpo femenino y la norma de la superioridad masculina" (“Qué es un feminicidio?" 37); a ambas se opone Blanca, quien desea escapar del poder de Chepo y vender por su cuenta la droga que corresponde al negocio de su pareja. El feminicidio funciona no sólo como el castigo impuesto a estos desórdenes, sino también como una amenaza que se potencializa hacia otros cuerpos. La investigadora argentina encuentra dos ejes mediante los cuales el cuerpo asesinado habla (La escritura 23): el primero es el eje vertical, que condena a la mujer a ser "contenida, censurada, disciplinada, reducida, por el gesto violento de quien reencarna [...] la función soberana" (ibídem); el segundo, el horizontal, se dirige a los pares "mostrando que merece [quien ejecuta], por su agresividad y poder de muerte, ocupar un lugar en la hermandad viril" ( "QQué es un feminicidio?" 41).

Cabe destacar que si bien es Chepo quien alienta el homicidio de Blanca -“ ${ }_{\mathrm{i} H a z} \mathrm{tu}$ jale Cuca! ¡A cortar!” (Zúñiga 75)-, es ella quien realiza el desmembramiento sobre la piel 
de la joven, mostrándose como un macho quien ha podido probar su virilidad en la carne de la víctima. Por medio de la penetración del cuchillo en la piel de Blanca, se forma un paralelismo con el acto sexual previo entre las dos mujeres, llevándolo a su conclusión y evidenciando el aspecto erótico y posesivo del asesinato, que puede calificarse entonces como crimen sexual:

La definición más sencilla presume que el crimen sexual es el asesinato después de la violación, aunque hay muchos crímenes en los que se supone que no ha habido una penetración de la víctima. Sin embargo, la mutilación de los genitales y los pechos, la forma como son utilizadas las armas punzocortantes y algunos otros objetos en los cuerpos de las víctimas no dejan lugar a dudas de que se trata de un motivo sexual (Monárrez 95).

La penetración de Blanca es múltiple: a pesar de la ausencia del falo -suplantado por el cuchillo, como ya se ha mencionado-, Cuca se apodera de sus genitales cuando "le baja la mano al sexo" (Zúñiga 71) y cuando la apuñala; Chepo, por su parte, cuando la toca; Tony, cuando la acosa. El cuerpo asesinado es entonces considerado "menos que mujer" (Monárrez 95): se arroja como si fuera basura. El cuerpo de Blanca asimila al de las muñecas: el desmantelamiento de sus miembros la deshumaniza y, convertido en objeto, se mimetiza con éstas al ser encerrada en la misma maleta que las transportaba.

\section{Poder y construcción del miedo y espacio}

La contracultura propuesta por Sol blanco, donde se instala el fenómeno del narcotráfico, se subyuga al sistema brutal que Sayak Valencia denomina "capitalismo gore". Así, mediante sus herramientas - prácticas ultraviolentas cuyo objetivo es el hacerse de capital (Valencia, "En el borde" 256-257) - se gestionan los cuerpos en un doble sistema de violencia. Curiel y Salazar hacen la distinción entre la violencia subjetiva y la sistémica para denotar la relevancia de la estructura de trasfondo que socialmente la permite (24). De esta manera, los asesinatos no son el resultado de una motivación única y enteramente personal, sino que se instalan como parte de una planificación que busca en el espectáculo de la muerte la producción de efectos aterradores (Diéguez, "Necroteatro" 11-12), promotores de la disposición de los cuerpos sin vida como parte de un macabro sistema comunicativo que comparte lenguaje y signos (10-11).

Sobre el lenguaje del miedo, Ahmed distingue entre “aquellos que están 'amenazados' y aquellos que amenazan" (120): Chepo se concibe como un personaje redondo gracias al 
miedo que profesa hacia el comandante -"pero no creas, el miedo es cabrón Cuca" (Zúñiga 59)-, mismo que debe liberar a través de la punición aplicada al cuerpo de Blanca.

Girard, quien introduce el estudio del chivo expiatorio como una figura en los paradigmas de la persecución, la identifica como parte de "las persecuciones colectivas o con resonancias colectivas" (21). Mientras que la primera se trata de una serie de violencias dirigidas por multitudes homicidas (Girard pone como ejemplo la persecución de los judíos), las segundas son aquellas que, aunque legales, se conforman por medio de la comunión histérica de la opinión pública (la persecución de las brujas). En ambas, la emergencia se convierte en un factor importante que motiva la acción de los agentes involucrados, pues surgen en medio de "períodos de crisis que provocaron el debilitamiento de las instituciones normales y favorecieron la formación de multitudes [...] susceptibles de sustituir por completo unas instituciones [...] o de ejercer sobre ellas una presión decisiva" (ibídem).

De esta manera, la contracultura en este ámbito se explica desde las crisis institucionales: el sistema debilitado es, a su vez, atacado por una contracultura que ha surgido de él mismo. Dicho ataque se manifiesta por medio de una serie de violencias -crímenes contra seres indefensos, crímenes sexuales y crímenes religiosos (25) - que "lesionan los fundamentos mismos del orden cultural, las diferencias familiares y jerárquicas sin las cuales no habría orden social" (ibídem). La impunidad propuesta por el sistema cerrado de la narcocultura (Diéguez, "El cuerpo roto" 161) necesita concretarse en la captura del chivo expiatorio, es decir, aquel de quien:

no está demostrada su relación directa con el acto violento, pero cuya función principal es la de tranquilizar, frenar, dar cauce al alboroto colectivo de una población que se encuentra en él, sin demostrar culpabilidad, un actor que libera la efervescencia justiciera; es decir, en quien se justifica toda práctica o acto de autorreclusión por considerarlo la manifestación de una amenaza latente (Curiel y Salazar 26).

Así pues, el chivo expiatorio es uno de los actores de la violencia (25-27): Tony responde a este papel, mientras que Chepo y Cuca al del sicario, Blanca al de víctima y como personajes contextuales se presentan el comandante y los policías de los retenes, quienes "favorecen y resguardan la realización" de los actos violentos (ibídem). La captura de un chivo expiatorio abona al bienestar de los altos mandos del mundo del sicariato, manteniendo en calma los más altos escalones de la violencia sistémica. Como si hubiese un sólo agente que representara el veneno, "los perseguidores siempre acaban por convencerse de que un pequeño número de individuos, o incluso uno solo, puede llegar pese a su debilidad relativa a ser extremadamente nocivo para el conjunto de la sociedad" (Girard 25). Debido a esto, el ejér- 
cito y la policía judicial federal se han utilizado para combatir únicamente al último eslabón de la cadena (Astorga 33) por medio de la captura de "algunas cabezas 'plebeyas"' (77): la captura de Tony, cuya presencia en la falsa escena del crimen parece cronometrada, da pie a la seguridad de Chepo y Cuca, quienes podrán seguir delinquiendo sin repercusiones. Así el agente que se transformará en el chivo expiatorio contiene tanto las características de la víctima (es el personaje masculino que se ha feminizado) como las del victimario (Girard 32), pues ha convertido, de igual manera, a Blanca en su objeto de deseo.

La sistematización del miedo, pues, se percibe alrededor de una serie de agentes que permiten la generación y permanencia de un ciclo: el terror surge, se ejecuta a un chivo expiatorio, y se aligera el caos temporalmente, por lo menos hasta que el terror vuelve a surgir de las manos de alguno de los seres de la escala superior. Debido a esto, es frecuente que en las poéticas sobre el narcotráfico se encuentren personajes letrados como actores esenciales cuya importancia consiste en el recuento de los daños, siempre en la forma del halago hacia el narco quien, las más de las veces, ha comisionado la noticia (Fuentes 49). En Sol blanco, el sonido proveniente del televisor ejecuta ese papel en tanto se coordina y sincroniza con las explosiones violentas de Chepo y Cuca, los dos personajes masculinizados dentro de la obra; así, al instante en que Chepo golpea el aparato del cuartucho de Cuca, se escucha al cronista que relata el partido de futbol: “iHijo, qué golpe, eso amerita expulsión o por lo menos tarjeta...!" (64), exaltando el alcance del golpe de quien es el cabecilla en turno. Lo mismo sucede, y de manera bastante más alarmante, cuando "Blanca patalea, intenta zafarse. Es levantada en vilo y azotada con fuerza sobre la televisión" (75), el cronista celebra la violencia infligida sobre su cuerpo: “¡Gool! ¡Goool! ¡Gooool!” (ibídem).

En Sol blanco, el miedo y el espacio se construyen como reflejos el uno del otro. De esta manera, donde hay miedo existe también un espacio particular que se configura según el miedo planteado. Ya Curiel y Salazar consideran que "nuestros escenarios cotidianos se caracterizan por la presencia de lo violento" (23), lo que ha provocado reacciones específicas para cada lugar. Kevin Lynch considera que las imágenes espaciales, además de servir como referencias prácticas se convierten en estímulos emotivos para el individuo (13), estímulos que pueden ser compartidos por los integrantes de un mismo grupo (16). De acuerdo con la percepción contracultural de los personajes, en lugar de recurrir a la automática "búsqueda de la calle 'principal"' (66), los sujetos endriagos de Sol blanco encuentran en la periferia un lugar seguro. Así, el hogar de Cuca se significa en relación con los individuos que se acercan a él: aunque para Blanca en un principio la casa periférica resulta un refugio - "ahí estaré más segura” (Zúñiga 55), advierte Blanca a Tony-, tan pronto los personajes masculinos la invaden se convierte en la amenaza donde el personaje encontrará la muerte. Esta periferia se convierte en "una tierra de nadie" (81), 
donde los cuerpos victimizados no encuentran la justicia. El miedo se construye en tanto Blanca se enfrenta a Cuca y Chepo: el deseo viril de poseerla se resuelve en la amenaza de "absorber al yo", de "verse incorporado por el cuerpo del otro" (Ahmed 107).

La discordia que existe entre los personajes respecto a la posesión de Blanca permite que ella encuentre refugio en un "objeto de amor, que se convierte en una defensa contra la muerte" (113). Blanca transita entre la cercanía con Cuca y con Tony: en ella encuentra el refugio de lo femenino - "Nunca te voy a olvidar" (Zúñiga 71), le confiesa culminado el acto sexual- y en Tony ve la posibilidad del escape -"No puedo regresar con Chepo, ya sabe..." (54)-.

El resto de los espacios se configuran también según la percepción de los personajes. Lynch identifica una serie de elementos propios de la ciudad: entre ellos destacan las sendas y los nodos: las primeras se refieren a conductos que permiten la movilidad (62); los segundos son las convergencias de estas sendas (ibídem). El transporte resulta primordial en Sol blanco en tanto representa el tráfico de las muñecas cargadas con cocaína. Sin embargo, se muestra aún más decisivo en los nodos, debido a que ellos adquieren una personalidad propia al relacionarlos Blanca con el miedo estimulado por la amenaza de los retenes. Los caminos se vuelven, así, un foco de intimidación donde el crimen de portar droga no representa la principal preocupación, sino la posibilidad del hostigamiento sexual (Zúñiga 69-70). Lynch plantea también la existencia de mojones, "puntos de referencia que se consideran exteriores al observador" (98): las garitas por las que Tony transita permiten identificar el lugar fronterizo. Esto propicia que los espacios de Sol blanco sean reconocibles: ubicados en Ciudad Juárez, los personajes se desenvuelven en la ciudad sin necesidad de nombrarla.

\section{Conclusiones}

En su manifiesto sobre el ciclo escénico de 1995-97, Vicente Leñero consideró que el Teatro Clandestino daría como resultado obras "destinadas a olvidarse y desaparecer [...] pero que cumplan el propósito de testimoniar, hoy, lo que padecen los mexicanos" ("Manifiesto” 15). La obra Sol blanco que, como se dijo, formó parte de dicho ciclo, fue publicada también en la Obra reunida de Antonio Zúñiga. Aunque pareciera que su existencia, como lo pronosticó Leñero, fue olvidada, sostengo que Sol blanco sigue vigente. No sólo retrata la frontera como un espacio donde la injusticia y la impunidad encuentran cabida gracias a un sistema que así lo ha planteado, sino que retoma problemáticas que por ser tabú permanecen silenciadas: el papel de las mujeres dentro del mundo del narcotráfico, los feminicidios efectuados contra aquellas que se encuentran en calidad de "delincuentes", negando así cualquier posibilidad de justicia, y los sacrificios perpetrados por religiosida- 
des alternas, de los cuales poco se habla, encasillándolos en lo sobrenatural y antinatural y negando su probable relación con el sistema capitalista y patriarcal.

Sol blanco acierta, además, en la construcción de sus personajes arquetípicos, que reaccionan únicamente cuando el más débil entre ellos se levanta. Los personajes se conforman a partir de los imaginarios sociales edificados alrededor de la imagen del narcotraficante: el discurso oficial, encabezado por las autoridades, se enfrenta con la identidad que proyectan los miembros del sicariato, por lo que los personajes construidos por Zúñiga contribuyen a la puesta en duda de su verdadera identidad, criticando de manera efectiva lo que el imaginario colectivo ha planteado sobre los narcotraficantes. También, acierta en el planteamiento de un sistema que no por ser contracultural deja de ser machista: al contrario, los personajes se polarizan hacia lo masculino o lo femenino en tanto cada una de estas categorías representa la oportunidad de continuar sobreviviendo. Así, la libertad se antoja un constructo masculino mientras que el feminicidio parece convertirse en el resultado directo de la desobediencia femenina. Las sexualidades se esbozan como momentos límite dentro de la obra, a partir de los cuales los personajes que detentan la masculinidad parecen tener más o menos poder en relación con Blanca, cuya posesión, al igual que la posesión de las muñecas, viriliza al individuo. Blanca se entiende como una mujer-trofeo cuya ostentación anima la masculinidad y, por tanto, el valor del individuo, ya sea Chepo, Cuca o Tony. Sin embargo, esta posesión conlleva también la degradación de Blanca: convirtiéndose en mula, la violación que sobre su cuerpo se ejerce es la prueba a la que se enfrentan las identidades del narcotráfico.

La narcocultura se entiende entonces como una inversión total de los valores de la cultura socialmente establecida. Se configura como una caricaturización de la realidad en tanto los sujetos crean una serie de identidades que comulgan entre la cultura de la que no pueden desprenderse y aquella promovida por el mundo del narcotráfico. La religión se vuelve esencial para subsistir dentro de este mundo, puesto que comprende una serie de comportamientos entre los que destaca el entendimiento que sobre la muerte se tiene. Llevada a la periferia, la narcocultura se ambiciona como un método por el cual puede llegarse a la riqueza fácil a través de un estilo de vida específico y una estética determinada. De esta manera, el nombre que ofrece Chepo a Blanca al pedirle que permanezca a su lado, "la reina de las polvaredas", no hace más que reafirmar la sistematización del narcotráfico: la polvareda no refiere únicamente al estado en el que se muestra la cocaína que Blanca transporta dentro de las muñecas, sino a la presencia riesgosa, casi efímera, que la mujer detenta en una ciudad tan cambiante que el polvo se levanta y huye. 


\section{Fuentes consultadas}

Acosta Viera, Judith Esmeralda. "Teorías sociales y mujeres que delinquen”. Mujeres en el tráfico minoritario de droga en la frontera México-Estados Unidos: exclusión, poder y riqueza. Tesis de maestría en Desarrollo Regional, El Colegio de la Frontera Norte, 2012, pp. 7-28.

Adame, Domingo. "Presentación”. Vicente Leñero y Antonio Zúñiga. Teatro clandestino, editado por Guadalupe de la Mora y Marco Antonio García Delgado. Ciudad Juárez: Alborde Teatro, 1999, pp. 11-13.

Ahmed, Sarah. La política cultural de las emociones. Traducido por Cecilia Olivares Mansuy. Ciudad de México: UnAm, 2015.

Astorga, Luis. Mitología del "narcotraficante" en México. Ciudad de México: unAm/Plaza y Valdés, 1995.

Becerra Romero, América Tonantzin. "Investigación documental sobre la narcocultura como objeto de estudio en México". Culturales, vol. 6, 2018, pp. 1-36.

Chesnut, Andrew. "Prólogo". La Santa Muerte. Espacios, cultos y devociones, coordinado por Alberto Hernández Hernández. Tijuana/San Luis Potosí: El Colegio de la Frontera Norte/El Colegio de San Luis, 2017, pp. 9-11.

Curiel García, Martha Mónica y Salvador Salazar Gutiérrez. "Colonizar la(s) fatalidad(es)". Ciudad abatida. Antropología de la(s) fatalidad(es). Ciudad Juárez: Universidad Autónoma de Ciudad Juárez, 2012, pp. 15-53.

Diéguez, Ileana. "El cuerpo roto/escenarios del necropoder". Cuerpos sin duelo. Iconografías y teatralidades del dolor. Monterrey: AunL, 2014, pp. 110-164.

Diéguez, Ileana, "Necroteatro. Iconografías del cuerpo roto y sus registros punitivos". Investigación Teatral, vol. 3, núm. 5, 2013-2014, pp. 9-28. Disponible en línea: https://investigacionteatral.uv.mx/index.php/investigacionteatral/article/ view/951

Fuentes Kraffczyk, Felipe Oliver. Apuntes para una poética de la narcoliteratura. Guanajuato: Universidad de Guanajuato, 2013.

Galicia, Rocío. "Asimilación de la realidad política en la dramaturgia y formación de teatros regionales. Teatro del Norte". Cambios paradigmáticos del teatro mexicano. Siglos XX y XXI, compilado por Gabriel Yépez. Ciudad de México: CITRU, 2013, citru.inba. gob.mx/publicaciones/libros/electronicos/ebook3/43.html, consultado el $10 \mathrm{de} \mathrm{ju-}$ lio de 2020.

Galicia, Rocío, "La dramaturgia actual del Norte de México". Banco de recursos, weknow, recursos.salonesvirtuales.com/assets/bloques//rocio_galicia1.pdf, consultado el 10 de julio de 2020 . 
Galicia, Rocío. "Los santos apócrifos en la dramaturgia del norte de México". KARPA 2.2.

Journal of Theatricalities and Visual Culture, 2009, www.academia.edu/7737338/Galicia_Roc\%C3\%ADo_Los_santos_ap\%C3\%B3crifos_en_la_dramaturgia_del_Norte_ de_M\%C3\%A9xico_, consultado el 12 de agosto de 2020.

Girard, René. "Los estereotipos de la persecución”. El chivo expiatorio. Traducido por Joaquín Jordá. Barcelona: Anagrama, 1986, pp. 21-34,

Hernández Hernández, Alberto. "La Santa Muerte. Espacios cultos y devociones". La Santa Muerte. Espacios, cultos y devociones. Tijuana/San Luis Potosí: El Colegio de la Frontera Norte/El Colegio de San Luis, 2017, pp. 13-29.

Jiménez Valdez, Elsa Ivette. "Mujeres, narco y violencia: resultados de una guerra fallida". Región y sociedad, núm. 4, 2014, pp. 101-128.

Leñero, Vicente. “Todos somos Marcos”. Vivir del teatro. Ciudad de México: FCE, 2012, 0-ebookcentral-proquest-com.lib.utep.edu/lib/utep/detail.action?docID=4559434, consultado el 10 de octubre de 2019.

Leñero, Vicente. "Manifiesto del Teatro Clandestino". Teatro clandestino, editado por Guadalupe de la Mora y Marco Antonio García Delgado. Ciudad Juárez: Alborde Teatro, 1999, p. 15.

Lynch, Kevin. La imagen de la ciudad. Traducido por Enrique Luis Revol, Barcelona: Editorial Gustavo Gili, 2013.

Monárrez, Julia. "El feminicidio sexual sistémico: de lo general a lo particular". Trama de una injusticia. Feminicidio sexual sistémico en Ciudad Juárez. Tijuana/Ciudad de México: El Colegio de la Frontera Norte/Porrúa, 2009, pp. 89-149.

Moreno, Iani del Rosario. "Narcoteatro: An Aesthetic of Fear". Theatre of the Borderlands. Conflict, Violence and Healing. Lanham: Lexington Books, 2015, pp. 115-160.

Nieto, Omar. "Literatura y narcotráfico: los primeros encuentros". Milenio, 21 de febrero de 2015, www.milenio.com/cultura/literatura-y-narcotrafico-los-primeros-encuentros, consultado el 10 de julio de 2020.

Ovalle, Liliana Paola y Corina Giacomello. "La mujer en el 'narcomundo'. Construcciones tradicionales y alternativas del sujeto femenino". La Ventana. Revista de Estudios de Género, núm. 24, 2006, pp. 297-318.

Partida Tayzan, Armando. "La cultural regional: detonador de la dramaturgia del Norte". Latin American Theatre Review, vol. 36, núm. 2, 2003, pp. 73-93.

Rascón Banda, Víctor Hugo. "Sol blanco”. Proceso, 20 de diciembre de 1997, www.proceso. com.mx/177129/sol-blanco, consultado el 30 de septiembre de 2019.

Salcedo, Hugo. "Teatro y literatura dramática en el norte de México”. Jornada Semanal, 27 de mayo del 2001, www.jornada.com.mx/2001/05/27/sem-salcedo.htm, consultado el 10 de julio de 2020. 
Segato, Rita Laura. La escritura en el cuerpo de las mujeres asesinadas en Ciudad Juárez. Territorio, soberanía y crímenes de segundo estado. Buenos Aires: Tinta Limón, 2013

Segato, Rita Laura. “Qué es un feminicidio?”. Fronteras, violencia, justicia: nuevos discursos, compilado por Marisa Belauteguigoitia y Lucía Melgar. Ciudad de México: UNAM, 2008, pp. 35-48.

Valencia, Sayak. "This is what the worship of death looks like: Capitalismo Gore, TLCAN y máquina feminicida". iMex 9, 2016, pp. 106-118.

Valencia, Sayak. "En el borde del border me llamo Filo: Capitalismo gore y feminismo". Discursos fronterizos de la cultura popular, compilado por Clara Eugenia Rojas Blanco, vol. 1. Ciudad Juárez: Universidad Autónoma de Ciudad Juárez, 2010, pp. 251-278.

Valencia, Sayak. Capitalismo gore. Barcelona: Melusina, 2010.

Vargas Montero, Guadalupe. "De devoción tradicional a culto posmoderno. La Santa Muerte en el norte y sureste mexicano (Ciudad Juárez y Veracruz)". La Santa Muerte. Espacios, cultos y devociones, coordinado por Alberto Hernández Hernández. Tijuana/San Luis Potosí: El Colegio de la Frontera Norte/El Colegio de San Luis, 2017, pp. 109-137.

Zavala, Oswaldo. "Introducción. La invención de un enemigo formidable". Los cárteles no existen. Narcotráfico y cultura en México. Barcelona: Malpaso, 2018, pp. 9-24.

Zúñiga, Antonio. "Sol blanco". Teatro clandestino, editado por Guadalupe de la Mora y Marco Antonio García Delgado. Ciudad Juárez: Alborde Teatro, 1999, pp. 47-66.

Washington Valdez, Diana. "Ciudad Juárez y la cultura del sacrificio". Fronteras, violencia, justicia: nuevos discursos, coordinado por Marisa Belausteguigoitia y Lucía Melgar. $2^{\text {a }}$ ed. Ciudad de México: unAm, 2008, pp. 49-65. 